\title{
Toward a Redefinition of Yes/No Questions
}

\author{
Julia Hirschiberg \\ Department of Cumputer and Information Science \\ Moore School/D2 \\ University of Penusylvania \\ Philadelphia, PA 19104
}

\begin{abstract}
While both theoretical and empirical studies of questionanswering have revealed the inadequacy of traditional definitions of yes-no questions (YNQs), little progress has been made toward a more satisfactory redefinition. This paper reviews the limitations of several proposed revisions. It proposes a new definition of YNQs based upon research on a type of conversational implicature, lermed here ocalar implicature, that helps define appropriate responses to YNQs. By representing YNQs as ecalar queries it is possible to support a wider variety of system and user respunses in a principled way.

I INTRODUCTION

If natural language interfaces to question-answering systems are to support a broad range of responses to user queries, the way these systems represint queries for response retrieval should be rexamined. Theorists of question-answering commonly define questions in terms of the set of all their possible (true) answers. Traditionally, thry have defined yes-no questions (YNQs) as propositional queations (PF) or as a special type of alternative question (?P $\vee$ ?Qj, in which the second alternative is simply the negation of the first (?P $\vee ? \neg P)$. So Does Mary like skiing?' would be represented as Plike(Mfary,skiing) or Plike(Mrary,ekiing) $\vee$ Phlike(Mary,skiing) and the range of appropriate responses would be yes, no and, possibly, unknoun. However, both theorctical work and empirical studies of naturally occurring questirn-answer exchanges have shown this approarh to be inadequate: $Y c a, n o$, and unkinown form only a small portion of the set of all appropriate respunses to a YNQ. Furchermure, for some YNQ's, none of these simple direct responses alone is appropriate.
\end{abstract}

While it is widely recognized (Hobbs, 1979, Pollack, 1982) that indirect respouses ${ }^{1}$ to YNQs represent an important option for respondents in natural discourse, standard theories of questionanswering have not breen revised accordingly. A practical consinurnce surfaces when attempts are made to support indirect responses to YNos computationally. For lack of alternative representations, question-answering systerns which would permit indirect responses must still represent YNQs as if the direct responses were the 'norm', and then resort to ad hoc mantipulations to generate second-class 'indirect' responses. thus perpetuating an asymmrtric distinction between 'direct' and 'indirect' responses. However. research under way on how a type of generalized conversational implicature, termed here ocalar implicature, can be used to guide the generation and interpretion of indirect responses to $Y N Q$ s suggests a revised representation for YNQs which accommodates a wide variety of responses in a uniform way

II CURRENT REPIRESENTATIONS OF YNQS

Among stand:ard acrounts of YNOs, Hintikka's (Hintikls. 1978) is one of the simplest and mont widely accepted, cumbining the

IIndireet responses to YNQs are derined here as regpunses other than yee, no, or some exiression of ignorance. concepts of YNQ as propositional question and as alternative question; as such, it will be used below w represent traditional approsuthes in general. To define answerhood, the conditions under whick a response counts as an answet to is natural-langutige query, Hintikia divides querics into two parts: an imporative or optative operator (!), roughly expressing 'bring it about that', and a desideratum, a specification of the equistenic state a questioner desires. For Hintikia, a YNO is a special case of altertaitive question in which the negalive allernative 'or not $P$ ' has been suppressed. So the desideratum of a YNQ is of the firm (I know that P) $\vee$ (I knoki that $n(a+P)$, where neyt indicales the negation-forming process. 'Does Mary like skiing?' thus has as its desideratum I know that Mfary likes akiing or I know that Micry does not like skiing. or, unore coneisely, ( $K_{s}$ like(Mary,skiing) $V$ $\left.K_{S}\right\urcorner$ like/Mtry, whing). whore $\mathrm{K}_{\mathrm{s}}$ is the epistemic representation of 'S knows that'. The full sense of the query is then 'Bring it about that 1 know that Mary likes skiing or that I know that Mary does not like skiing:, which can be represented by ! $\left(K_{S} P \vee K_{S} \neg P\right)$. Possible respounes are simply $\{P, \neg P\}$, or $\{$ yes,no $\}$.

A. Hypothesis Confirmstion

Bolinger (Bolinger, 1978) has called such interpretitiuns iuto question by showing that YNOs may have very different meanings from their altirnativequestion counterparts; they also have inure restrictod paraphrase and intonation patterns. In Boliuger's vicw the torm yea-no query has hypnotized scholars into assuming that, simply because a class of question can be answered by a yes or no, these alternatives are criterial, and every $Y N Q$ is intended to rlicit one or the other. He proposes instead that YNQs be viewed as hy potheses put forward for confirnation, ameasment or disconfirmation - in any degrec. Thus, in Eolinger's exarnpli: (1), the

(1) Q: Do you like Honolulu?

R: Just a little.

questionet (Q)'s hypothesis 'you like Honoluiu' is atrended by the respondent (R) in a sesponse which is neither yes nere no but somewhere in between. In his example (2), Q's hypothesis 'it is

(2) Q: Is it difficult?

$R$ : It's impossible.

diffieult' is confirmed by $R$ 's assertion of a more positive response than a simple ycs.

White Bolinger makes a good case for the inadeguacy of standard views of YNos, the revision he proposes is itsolf t... linuted. 'It's

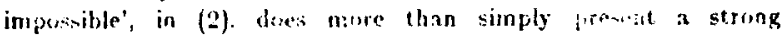
arfirmation of the hypothes is "it is difficult" - it provities new :ned unrequested though pertibent information. la fixct, strong affirmation' might better be frovided by a response such as 'I am absolutely sure it's difficult' than by the response lee siggests. And ther are equally appropriate responses 10 the pieries in (1) and (2) that are not easily explained in terms of degree of hypothesis confirmation, as shown in (3) and (4). 
(3) C: Do you likr ! fondulu?

a. K: I den't like llawaii.

b. R: I lik: Itils.

(1) Q: Is it dirticult?

a. 1 l: It could be

b. R: Mike says so.

Finally, Boinger does not propose a representation to accommodate bin hypothrsis-confirntation model.

B. Faruesid YNCR

Similarly, Kiffer (kiefer, 1980) points out evidence for the inadeguacy of the standard view of $\mathrm{YNC} s$, but proposes no unified solution. In a stuly of the indirect spcech acts that may be profurmed ly YVQt, he noten that certain YNQs, which he terms jocuesed INQ*, artually function as wh-questions. Focussed YNQs for Kinfer arr YiNQs that are marked in some way (apparently by strens to indirate a background assumption which $(?$ and $k$ typically share. For example, $(5 a)$ is not a forussed YNQ whik (shlflid) are. While any of the four may be answered with yre or

(5)

a. Is John leaving for Stociholin tomorrow?

b. Is John traving fur Stockholn TOMORROw?

c. Is John leaving for stockllol.M tomorruw?

d. Is JOHN loaving for Storkbolm tomorrow?

no, it is also posible that, if $\mathrm{Q}$ asks (5\%), she wanto $\mathrm{R}$ to answer the question 'When is John leaving for Stockholm?'; if she asks (5r) she may wabt to know 'Where is John going tomorrow?; and if she asks (5d) she may want to know' 'Who is leaving for Stockholm tomorrow? Thus a focussed YNQ resembles the wb-question that might be formed by replacing the forussed element in the desideratum with a corresponding Pro-clement. In Kiefer's analysis, only one cleitient can he focussed, so responses such as 'He's leaving for Paris 'Thuraday' will not be accommodated.

Although Kirfer does not propose a representation for focussed Yivgs, a disjunct rescmbling the desideratum of a wh-question might be added to the traditional representation to accommodate his third alternative: for (trd) this might take the form 'Is John leaving for Stockloolm tomorrow, or, if not, who is?' or, in Hintikka's notation.

$$
\begin{aligned}
& \text { ! K loaving(John,Stockholm,tomorrow) V } \\
& K_{Q} \text { ᄀleaving(John,Storkhalm,tonorrow) V } \\
& \exists x K_{Q} \text { leaving(x,Stockholm,tomorrow). }
\end{aligned}
$$

This representistion reflects another problem posed by Kiefer's analysis: the third disjunct is appropriate only when the sccond also is and not. when the direct response yes is true. For exantple, a response of 'Bill is' to (jd) seems to convey that John is not leaving for Stochholm tonmerow. Thus viewing some YNQs as wh-quretions requires a rather more complex representation than simply adding a wh-question as a third disjunct. ${ }^{2}$ In addition, defining different representations for various YNQ subtypes seems a less than satistaclory solution to the limitations presented by current representations of YNQs. A more unified solution to the problems identified by Bolinger and Kiefer would clearly be desirable. Such a solution is suggested by current research on the role conversational implicature plays in accounting for indirect responses to YNOs.

III CONVERSATIONAL IMPLICATURE AND YNQS

In a large cliss of inelirect respontes to YNQs, query and response cach refer to an cutity, attribute, state, activity, or event that can be vicwed as appearing on some ecale; such refereoces

In fact, the third disjuort rould have to be something like

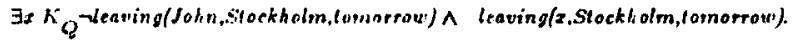

Brilie ideas outlined in the following stetion are discussed in more detail in (Hlirsthberg, 1084). will be tarmed scalars and responses in such exchanges will be termed scalar reoponses. ${ }^{3}$ In such scalar exchanges, questioners can infer both a direct response and additional implicit information from the unrequested information provided by the respondent. In (6) for example, $Q$ is entitled to infer the direct response no or $I$ don'? knou"

(fi) Q: Are mushrooms poisonous?

$R$ : Some are.

and the additional information that $R$ believes that there may be mushrooms that are not poisonous, wen though $3 x$ (mushroom(x) $\wedge$ poisonous $(x) j$ does not logically injly any of this information. Clearly 'Some are' is an appropriate response to the query - more appropriate in fact than a simple no, which might convey that no mushrooms are poisonous - but what makes it appropriate?

Grire's (Gricr, 1975) Cooperative Principle claims that, without contrary evidence, participants in conversation assume their partuers are trying to be cooprative. In consequence, they reconize certain conversational maxims, such as Grice's Maxim of Quantity

a) Make your contribution as informative as is required (for the current purposes of the exchange).

b) Do not make your contribution more informative than is required.

and his Maxim of Quality

Try to make your contribution one that is true.

a) Do not say what you believe to be false.

b) Do not say that for whicb you lack adequate evidence.

Speaker and hetarer's mutual recognitiou of these maxims may give rise to conversational implicatures: An utterance conversationally implicates a proposition $P$ when it conveys $P$ by virtue of the hearer's assumption of the speaker's cooperativeness. While a speaker may not always obey these maxims, the bearer's expectations are based on her belief that such conventions represent the norm.

A. Scalar Predication

Following Grice, Horn (Horn, 1972) observed that, when a speaker refers to a value on some scale defined by semantic entailment $t^{4}$, that value represents the lighest value on its scale the spraker can truthfulty affirm. The speaker is saying as much (Quantity) as she truthfully (Quality) can. Higher values on that scale are thus inplicitly marked by the speaker as not known to be the case or known not to be the case. ${ }^{5}$ Values lower on the scale will of course be marked as true, since they are entailed. Horn called this phenomenon ecalar predication, and Gazdar (Gazdar, 1979) later used a variation as the basis for a phenomenon he inrmed ecalar quantity implicature. Here a much revised and extended version will be termed ecalar implicature.

Horn's simple notion of scalar predication does provide a principled basis for intcrpreting $(0)$ and similar indirect responses to YNQs where scales are defined by entailment. Some is the highest value on a quantifier scale that $R$ can truthfully affirm. Truth-values of higher scalars such as all are either unknown to $R$ or believed by him to be false. Thus, if $Q$ recognizes $R$ 's implicature, roughly, 'As far as I know, not all mushrooms are poisonous', she will derive the direct response to her query as no or I don't know. $\mathrm{R}$ must believe either that some mushroms are not poisonous of that some mushrooms may not be poisonous.

\footnotetext{
${ }^{4} W$ semantically entails $T$ in $T$ is true whenever $W$ is.
}

${ }^{5}$ Whether a speaker implicates ignorance or falsity of a value is a subject of some disagreemant arnong Horn and those (Gazdar, 1070, Soames, 1082) who have taken up his basic notion. In (Hirschberg, 1084) 1 contend that such implicatures should be viewed as disjunctions, $K(\neg T) \vee \neg K(T)$, whicb may be disambiguated by the nature of the ordering relation or by the context. 
It is also important to note that, in (6), were $R$ simply to deny Q's query or to assert ignorance with a simple $I$ don't know, Q would be entitled, by virtue of the Conperative Principle, to assume that there is no scalar value whose truth $R$ can in fact affirm. That is, $Q$ can assume that, as far as $R$ knows, there are no musbrooms that are poisonous, for otherwise $R$ could commit bimself to the proposition that 'some mushrooms are poisonous'. More generaily then, $\mathrm{I}$ is obliged by the Cooperative Principle, and more esperially by Joshi's (Joshi, 1982) modification of Grice's Maxim of Quality: 'Do not say anything which inay imply for the bearer something which you the speaket believe to be false.', to provide $3 n$ indirect response in (6), lest a simple direct response entitle $Q$ to conclude some false implicatures. Thus indirect responses must be included among the set of all appropriate responses to a given YNQ, since in some cases they may be the most appropriale response $R$ can make.

B. Scalar Implicature

While scalar predication provides a principled explanation for (6), a revised and extended notion of sealar implicature can account for a much larger class of indirect responses to YNQs. It can also suggest a revised representation of YNQs in general based upon this enlarged class of appropriate responses.

Orderings not defined by entailment and orderings other than linear orderings, including but not limited to set/set-member, whole/part, process stages, spatial relationship, prerequisite orderings, entity/attribute, isa bierarchy, or temporal ordering, permit the conveyance of scalar implicatures in much the same way that the entailed quantifer scale does in (6): In (7) the set/ member

(7) Q: Did you invite the Reagans?

R: I invited Nancy.

(8) Q: Have you finished the manuscripl?

R: l've started a rough draft.

relaticonship orders the Reaynns and Nancy; $\mathrm{R}$ implicates that he has not invited Ronald, for instance. In (8), starting a rough draft precedes finishing a manuecript in the process of preparing a paper. So $Q$ is entitled to conclude that $R$ has not finished the manuscript or completed any later stage in this process, such as finishing the rough draft.

More formally, any set of referents $\left\{b_{1}, \ldots, b_{n}\right\}$ that can be partially ordered by a relation $\mathrm{O}^{6}$ can support scalar implicature. Any scale $S$ that permits scalar inplicature can be represented as a partially-ordered set. For any referents $b_{1}, b_{2}$ on $S, b_{2}$ is higher on $S$ than $b_{1}$ iff $b_{1} O b_{2}$; similarly, $b_{1}$ is lower on $S$ that $b_{2}$ iff $b_{1} O b_{2}$. Any pair $b_{1}, b_{2}$ of incomparable elernents (elements not ordered with respect to one another by $O)$ will be trmed alternate values with respect to $\mathbf{S}$. This redefinition of scale accommodates orderings such as those mentioned above, while exciuding orderings such as cycles, that do not permit scalar implicuture. It also helps define the interences licensed when $R$ aftirms a higher or an alternate value, or when he denies or asserts ignorance of lower, higher, or alternate values.

For example, $R$ affirms a higher scalar value than the value querrird in Bolisger's exumple reproduced in (2). If difficult and impossible are viewed on a scale defined in digrees of feasibility, then $Q$ can ronclude that by affirming the higher value $R$ has affirmed the luwer. Similiarly, $R$ may affirm an alternate value, as he does in (3h). Ir $R$ spes Honoluly and Hilo as both members of a set of Hawaiian cities, be can iffirm an unqueried set menber (Hilo) to deny a querind member (llawaii). The affirmation of an unqueried altirnate value generally conveys the talsity or R's ignorance of the queried value.

${ }^{\circ}$ A partial ordering may be defined as an irreflexive, esymnimerie, and transitive reiation.
Speakers inay also license scalar implicatlires by denying scalars. The dual to Horn's notion of affirning the highest affirmable value would be negating the lowest deniable scalar. In such a denial a speaker may implicate his affirmation or ignorance of lower scalars. So, in exchanges like (9a), a value higher than a queried value (here,

(9) Q: Did you write a check for the rent?

a. R: I haven't mailed it yet.

b. R: I haveu't signed it.

c. R: I didn't pay cash.

a stage in the process of mortgage payment) may be denied to convey the truth of the queried value. $R$ may also deny lower values (Ob) or allernate values (Mc).

So, indirect scalar responses may be defined upon a number of metrics and may involve the affirmation or negation of higher, lower, or alternate values. They may also involve the affirmation or denial of more than one scalar for a single yuery, as show $n$ (10). Assume that Mary and Joe are brother and sister and both are known to $Q$ and R. Also, Mary and Tin are fellow-workers with $Q$ and $R$. Then to $Q$ 's question in (10), $R$ may felicitously respond with any of the

(10) Q: Does Mary like skiing?

a. R: She loves irsuskating.

b. R: Joe loves cross-counlry.

c. R: Tim likes cross-country.

answers given - as well as 3 variety of ochers, such as 'She used to' of even 'Joe used to love ice-skating.' That is, $R$ may base his response upon any one or more scalars he perceives as invoked by Q's query. In addition, a single lexical jtesn (here Mary) may invoke nore than one scale: $R$ may view Mary as a member of is family or of a set. of fellow-workers, for example, to generate responsers (10b) and (10c), respectively.

C. A Scalar Representation of YNQs

Given this characterization of appropriate indirect responses, it is possible to model the exchanges presentand atove in the following way:

1. For some query uttered by $Q$, let $P \vee \neg P$ represent the query's desideratuin;

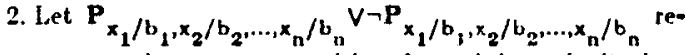
present the open propusition formed by substituting variables $x_{i}$ for each $b_{i}$ inirolicd by $P$ that $R$ perceives as lying on some seale $S_{i}$;

3. Then $P_{a_{1} / x_{1}, x_{2} / x_{2}, \ldots, a_{n} / x_{n}} \vee \neg P_{a_{1} / x_{1}, x_{2} / x_{3}, \ldots, a_{n} / x_{n}}$ defines the set of possible responses to $Q$ 's querry, whiete earh $a_{i}$ represents some scalar cooccurrirg with its corresponding $b_{i}$ on $S_{i}$.

4. A subset of these prissitic responses. the set of yossibie true responses, will be delierrined by $\mathrm{I}$ from his knowledge base, and an actual response serkerted.

In (6), for example, the desidesatum $\left(P \vee \neg P^{\prime}\right)$ of $C^{j}$ 's query is the generic '(all) mushrooms are poisonous' $V$ 'not (all) mushrooms are poisonous'. Here $\mathrm{R}$ might perceive a single scajar all lying on $a$ quantifier scale, none/some/all. So, ' $x_{1}$ mushroons are poisonous' $V$ 'not $x_{1}$ inushrooms are poisonous' represents the open propusition formed by substituting a variable for all in $P$, where $x_{1}$ ranges over the vilues on $S_{1}$, nom /somr/all. Then the set of powille respensens to $Q$ 's quecy, given $R$ 's choice of scalkr, is defined by the affirmation or ingation of earh of the possible instantiations of ' $a_{1} / x_{1}$ inushrooms atr poisonous', or the set (no mushrooms are prisonousisome mushrooms are poisonc,us,all mushrooms are poisonous, ᄀno mushrooms are poisonous, -some

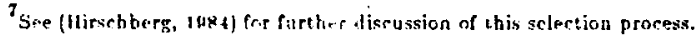


musiroums are poisonous, aail ravehroms are poisonous\}. The sel of positile true responses will be a sulset of this set, detrrmined by $K$ from bis knowledge base. Ninte that $a_{1}$ and $b_{1}$ may in fact be identical. Thus, the simple direct responses, equivairut to 'All mushrooms are poisonous' and 'Not all mushrooms are poisonous', are accomnodated in this schema.

Tbis characterization of potential responses suggests a new representation for YN(ss. loblswing Hintikks, one might paraphrase the qury in $(6)$ as "Bring it about that I know that $x_{1}$ mushroums are poivonous or that $I$ know that not $x_{1}$ mushrooms are poisonous", where $x_{1}$ ranges over the values on some scale $S_{1}$ upon which t!re qurried vilue some appears fassuming a manysurted epistemie Ingic). Thus the query might be represented as

! JS $S_{1} \exists x_{1}\left\{\right.$ sorke, $x_{1} \in S_{1} \wedge\left\{K_{Q}\left(x_{1}\right.\right.$ mushrooms are poiscolous $) \vee K_{Q} \neg(x$, mushrooms are poisonous $\left.\left.)\right\}\right\}$

For a query like that in (10), an appropriate representation might be:

$$
\begin{aligned}
& \text { ! } \exists S_{1} \exists x_{1} \exists S_{2} \exists x_{2} \exists S_{3} \exists x_{3}\left\{\text { Mary, } x_{1} \in S_{1} \wedge \text { love, } x_{2} \in S_{2}\right. \\
& \left.\wedge \text { skiing. } x_{3} \in S_{3} \wedge\left\{K_{Q}\left(x_{1} x_{2} x_{3}\right) \vee K_{Q} \neg\left(x_{1} x_{2} x_{3}\right)\right\}\right\} .
\end{aligned}
$$

I? niay then instantiate each variable with any value from its domain in his response.

In the gencral rase, then, YNQs might be represented as

$$
\begin{aligned}
& : \exists S_{1}, \ldots, \exists S_{n} \exists x_{1} \ldots, \exists x_{n_{n}}\left\{b_{1}, x_{1} \in S_{1} \wedge \ldots \wedge \wedge b_{n}, x_{n} \in S_{n} \wedge\right. \\
& \left\{K_{Q}\left(l^{\prime} x_{1}, \ldots, x_{n}\right) \vee K_{Q} \neg\left(P_{x_{1}, \ldots, x_{n}}\right)\right\} .
\end{aligned}
$$

This representalion shares some features of standard representitions of wh-djuestions, suggesting that it simply extends Kinfer's vipv of forumed YNQs to all YNQs. However, there are several signifianat distinctions between this representation and standard representations of wh-questions, and, thus, between it and Kiefer's suggestion. First, it restricts the domains of variables to scales invoked by corresponding swalars in the original queries desideratum and it includes a uegative disjunet. 'Do you like Ionolulu?' for example might have as its desideratum

$$
\begin{aligned}
& \exists S_{1} \exists x_{1} \exists S_{2} \exists x_{2} \exists S_{3} \exists x_{3}\left\{\text { you, } x_{1} \in S_{1} \wedge \text { like }, x_{2} \in S_{2}\right. \\
& \left.\wedge \text { Ilonolulu, } x_{3} \in S_{3} \wedge\left\{K_{Q}\left(x_{1} x_{2} x_{3}\right) \vee K_{Q} \neg\left(x_{1} x_{2} x_{3}\right)\right\}\right\},
\end{aligned}
$$

while the corresponding wh-questicn 'What do you like?' would have as its desideratum $\exists x K_{Q}$ (you like $z$ ). Second, the representation proposed here allow's for reference in a query to muluiple scalars, or, multiple focii, which Kiefer does not consider. Third, it aruids both the division of YNQs into focussed and nonforussed querins and the dependency between wh-responses and negative responses noted above; hence, the representation is simplet and more unified. So, YNQs are not represented as whquestions, altbough Kirfer's focussed YNQs can be accommodated in this more general representation, whicb I will term a ecalar representation.

\section{DISCUSSION}

A scalar representation of YNQs can accommodate a wide range of direct and indirect responses which are common in natural discourse but which current representations of YNQs cannot support. Of course, such a redefinition is no panacea for the limitations of current representations: In its current form, for instance, there are some appropriate responses to indirect speech acts, such as (11), which it

(11) Q: Can you tell me the time?

$$
\text { R: It's } 5: 30 \text {. }
$$

will not support. In otler exchanges, such as (12), the notion of scale may scem less than natural. where a srale like aftributes of a

(12) $Q:$ Is she pretty?

Ki: She's married.

potcnlinl dale: \{protly, unmarried,... must be postulated to accommodate this query in the the representation proposed here.
Too, the actual representation of a partieular query may vary according to participants' differing perception of scalars invoked by it, as shown in (10). Because scales are not defined in absolute terms, it is difficult to determine even an abstract specification of the set of all possible responses to a given query; should temporal and modal variables always be understood as implicitly evoked by any query, for example, as in (13)? However, if broad categories of such

(13) Q: Is Gloria a blonde?

a. R: She used to be

b. IR: She could be.

'understood' scales can be identified, much of this difficulty might be alleviated. The representation proposed here does accommodate a far larger class of appropriate responses than representations previously suggested, and accorumodates them in a unified way. With further refinement it promises to provide a useful tool for theoretical and computational treatments of YNQs.

\section{ACKNOWLEDGEMENTS}

I would like to thank Aravind Joshi, Kathy McCoy, Martha Pollack, Sitaram Lanka, and Bonnie Webber for their comments on this paper.

\section{PEFERENCES}

Bolinger, D. Yes-No Questions Are Not Alternative Questions. In Hiz, H. (Ed.), Qutstions. Dordrecht (Neth): Reidel, 1978.

Gazdar, G. A Solution to the Projection Problem. In Oh, C.-K. and Dinneen, D. (Eds.), Syntax and Semantics. New York: Academic Press, 1979.

Grice, H. P. Logic and Conversation. In Cole, P. and Morgan, J.L. (Eds.), Syntax and Semantics. New York: Academic Press, 1975.

Hintikka, J. Answers to Questions. In Hiz, H. (Ed.), Questions. Dordrecht (Neth.): Reidel, 1978.

Hirscliberg. J. Scalar Inplicature and Indirect Responses to YesNo Queetions (Tech. Rep. MS-ClS-84-9). University of Pennsylvania, April 1981.

Hobbs, J. and Robinson, J. Why Ask? Discourse Processes, 1979, Vol. 2 .

Horn, L. R. On the Semantic Properties of Logical Operators in English. Doctoral dissertation, University of California at Los Angeles, 1972.

Joshi, A.K. The Role of Mutual Beliefs in Question-Answer Systems. In Smith, N. (Ed.), Mutual Belief. New York: Academic Press, 1982.

Kiefer, F. Yes-No Questions as WH-Questions. In Searle, J., Kiefer, F., and Bierwisch, J. (Eds.), Speech Act Theory and Pragmatics. Dordrecht (Neth): Reidel, 1980.

Pollack, M. E., Hirschberg, J., and Webber, B. User Participation in the Reasoning Processes of Expert Systems (Tech. Rep. MS-CIS-82-9). University of Pennsylvania, July 1982. A shorter version appears in the AAAl Proceedings, 1982.

Soames, C. How Presuppositions Are Inherited: A solution to the projection problem. Linguistic Inquiry, 1982, 19(3), 483-545. 